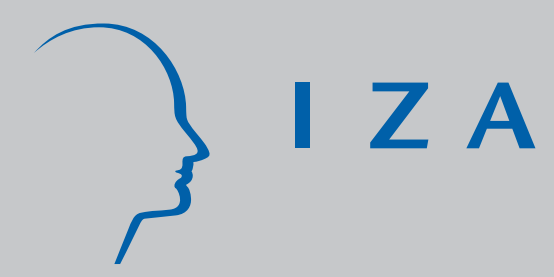

IZA DP No. 3196

Hearing Loss and Disability Exit:

Measurement Issues and Coping Strategies

Vibeke T. Christensen

Nabanita Datta Gupta

Martin V. Rasmussen

November 2007 


\title{
Hearing Loss and Disability Exit: Measurement Issues and Coping Strategies
}

\author{
Vibeke T. Christensen \\ Danish Institute of Governmental Research \\ Nabanita Datta Gupta \\ Danish National Centre for Social Research \\ and IZA \\ Martin V. Rasmussen \\ Employment and Integration Administration \\ of the Municipality of Copenhagen
}

Discussion Paper No. 3196
November 2007

IZA

P.O. Box 7240

53072 Bonn

Germany

Phone: +49-228-3894-0

Fax: +49-228-3894-180

E-mail: iza@iza.org

Any opinions expressed here are those of the author(s) and not those of the institute. Research disseminated by IZA may include views on policy, but the institute itself takes no institutional policy positions.

The Institute for the Study of Labor (IZA) in Bonn is a local and virtual international research center and a place of communication between science, politics and business. IZA is an independent nonprofit company supported by Deutsche Post World Net. The center is associated with the University of Bonn and offers a stimulating research environment through its research networks, research support, and visitors and doctoral programs. IZA engages in (i) original and internationally competitive research in all fields of labor economics, (ii) development of policy concepts, and (iii) dissemination of research results and concepts to the interested public.

IZA Discussion Papers often represent preliminary work and are circulated to encourage discussion. Citation of such a paper should account for its provisional character. A revised version may be available directly from the author. 
IZA Discussion Paper No. 3196

November 2007

\section{ABSTRACT \\ Hearing Loss and Disability Exit: Measurement Issues and Coping Strategies}

Using unique representative data containing self-reported functional and clinically measured hearing ability for the Danish population aged 50-64, we estimate the effect of hearing loss on receipt of disability benefits accounting for potential endogeneity of functional hearing. Our identification strategy involves simultaneous estimation of labor supply, functional hearing and coping strategies i.e. using assistive devices at work or informing one's employer about the problem. We find that functional hearing disability significantly increases the likelihood of receiving disability benefits for both men and women. Using assistive devices at the work place decreases the likelihood of going on disability for both genders, whereas telling the employer about the disability increases disability-related exit for both genders, but considerably more so for women.

JEL Classification: J26, I12

Keywords: hearing loss, disability exit, functional hearing, clinical audiometry test, gender differences

Corresponding author:

Nabanita Datta Gupta

Danish National Centre for Social Research

Herluf Trolles Gade 11

DK-1052 Copenhagen K

Denmark

E-mail: ndg@sfi.dk 


\section{Introduction}

Hearing loss has been identified as one of the most common chronic health conditions of adulthood, estimated to affect around $16 \%$ of the adult population (Shield 2006; Wilson et al. 1999). Its prevalence rises steadily with age, and increases steeply from about age 55 (Ries 1994) so that almost a third of the 50-plus population has some degree of hearing difficulty. With the expected growth in the elderly population and the younger generation's increased exposure to noise via media consumption and the use of e.g. mp3-players (Morata 2007; Fligor \& Cox 2004) the prevalence of hearing problems can be expected to escalate in the upcoming years.

Because it is an impairment that affects the very core of human existence-the ability to communicate-it deeply impacts not only the hearing impaired individual but also his or her family, colleagues, and social surroundings, and depending on the severity of the disability, can result in feelings of frustration, anxiety, low self-esteem, and social isolation (Kochkin \& Rogin 2000; Crandell 1998; Danermark 1998; Mulrow et al. 1990; Bess et al. 1989; Brooks \& Ellis 1982). A hearing impairment can therefore profoundly impact the individual's social, psychological and physical well-being not only in the private sphere but also at work, where having a hearing impairment can result in a loss of job function, lowered job satisfaction, and lowered labor market participation.

The vast majority of jobs these days require communication skills and the ability to engage in discussions and dialogue with colleagues, customers or collaborators. When one has problems with one's hearing, workplace information may be lost; but equally, if not more importantly, engaging in small talk around the water-cooler or during lunch becomes difficult. The prevalence of workplace difficulties caused by hearing problems is well documented: research indicates that people with hearing impairments are more likely than people without such problems to be unemployed or take early retirement so that overall labor force participation is reduced for the hearing impaired compared to the normal hearing (Christensen 2006; Kochkin 2005; Ries 1994).

Alternative coping strategies such as the use of assistive devices, or informing one's surroundings about the hearing disability can be used to overcome the difficulties and barriers arising as a result of the hearing loss. Some hearing impaired persons talk freely about their disability, seeking understanding and help from their surroundings, 
whereas many others conceal their impairment and try to downplay its consequences. In contrast to most other impairments, a hearing loss is not visible and is therefore more easily hidden. Concealment of the impairment seems to be a coping strategy that many people with a hearing loss instinctively and self-protectively use. According to Goffman (1964, 1959), individuals establish and maintain social identity through interaction with others and use different strategies to appear 'normal' and non-deviant. Hearing impairments are often associated, in a prejudicial way, with being physically old or mentally slow. Because of these stigmas, many hearing impaired persons possibly feel reluctant to acknowledge or recognize their own hearing problems in order to protect their own self-image (Martin et al. 2000; Hétu 1996; Hallberg 1992; Hétu et al. 1990). This strategy, however, does not solve the core issue in dealing with a hearing loss, i.e., the communication difficulties that the lack of hearing causes. What occurs instead is that the hearing impaired person's co-workers and colleagues perceive him or her as being arrogant, aloof, or unfriendly, because he or she does not always respond as expected, lowering productivity and job satisfaction even further for the hearing impaired.

There appear to be large gender differences when it comes to hearing abilities and coping strategies. Men generally tend to get hearing problems earlier in life and more severely than women do (Duijvestijn et al 1999; Sininger et al 1998). Additionally, men and women seem to be affected by their hearing problems in different ways (Christensen, 2006) and the preferred coping strategies differ between genders with women e.g. more often informing others and using verbal strategies (Hallberg, 1999; Garstecki \& Erler, 1998). Furthermore, some studies show that men often are more unwilling than women to acknowledge their hearing difficulties (Uchida et al. 2003; Kricos 2000; Hétu et al. 1990).

The aims of this paper are twofold: First, we seek to investigate to what extent hearing difficulties lead to early retirement through disability benefits. In Denmark disability benefits are granted to people who are unable to work or support themselves because of physical, psychological, or social reasons. As a recipient of disability benefits is only allowed very limited labor income in addition to the disability benefits, receipt of disability benefits in Denmark is equivalent to early exit from the labor market (Ministry of Social Affairs 2002). Given that it is very difficult to be granted 
disability benefits solely on the grounds of a hearing disability, we hypothesize that the main effect of a hearing difficulty will be through the higher probability of application to disability benefits for the hearing impaired compared to those with normal hearing. As self-reported functionally measured hearing is likely to be endogenous to labor supply, we simultaneously estimate receipt of disability benefits and functional hearing using hearing aids as an instrument for the latter.

Second, we examine the effects of the acknowledgment of personal hearing problems and the use of different coping strategies on labor force participation. The coping strategies included are: informing one's employer about the hearing difficulties and the use of different assistive devices at work such as phone amplifiers or wire loops. As informing one's employer may also be endogenous to labor supply, we simultaneously estimate a three-equation model of receipt of disability pension, functional hearing and coping strategies.

We use unique Danish survey dataset containing questions about labor force participation, work experience, health, and functional hearing difficulties. In addition to answering the survey questions, all respondents underwent a clinical audiometric hearing test. A total of 2,407 respondents between the ages of 50-64 participated, constituting a survey sample that approximately represents the Danish population within this age group.

Previous research on the hearing impaired based on representative data have mostly used self-reported hearing difficulties to identify the hearing impaired (Access Economics 2006; HRF 2005; Kochkin 2005; Ries 1994). By doing so two possible problems arise. First, hearing disability might be measured with error due to the possibility of unacknowledged hearing loss in these studies which may bias its effect on labor force participation down towards zero. Second, a self-reported hearing problem will likely be endogenous to labor supply as individuals may report hearing loss e.g. to justify collecting disability benefits.

Our data include both a subjective self-reported measurement of the respondent's functional hearing in everyday life as well as a clinical measurement of the respondent's average hearing threshold obtained through an audiometric hearing test. By including both measurements, we are able to account for the effect on labor market participation of an unacknowledged and unrecognized hearing impairment as well 
account for the bias which arises when measurements of hearing loss are self-reported only. To our knowledge, no other studies have systematically addressed these issues making this a more reliable and accurate study of the effects of hearing loss on labor supply than those in the previous literature.

Of the many findings that result from our study, a major one is that a functional hearing disability significantly increases the individual's likelihood of receiving disability benefits, while a clinically measured hearing loss only has an effect when it is accompanied by other health problems. We also find somewhat differing results for men and women, with the largest gender differences obtained in the case of coping strategies.

In section II we describe the details of the dataset, including a discussion of our definition of a hearing disability and the measurements we access. In section III we present our empirical model, while we discuss our estimation results in section IV. Section V concludes.

\section{Data and approach}

\section{A. Survey data}

Despite the large numbers of people who are affected by hearing difficulties, few studies uncovering the magnitude of the problem have used representative data for country populations. Studies dealing with hearing impaired persons most often collect their data among individuals already in treatment for their hearing problems. The data therefore includes only people who have acknowledged their hearing difficulties and have acted upon them. As mentioned earlier, as hearing difficulties are often met with prejudice, this gives people few incentives to recognize and admit to the disability. When a survey includes only individuals who have acted upon their hearing problems, it ignores the substantial number of people living with a hidden hearing disability. In this study we use a survey data set including 2,407 respondents representative of the Danish population between 50 and 64 years of age. Personal information on about 3,000 people in that age range were drawn from Statistics Denmark's administrative data registers which contain the Central Person Registry (Det centrale personregister) or CPR identifier for every person in the country and which researchers can therefore 
use to link all appropriate individuals for their survey. This method ensures a completely representative population sample of the Danish population within the chosen age group. Out of the 3,000 individuals in the sample, we obtained answers from 2,407, yielding a response rate of 80 percent.

The survey, which we conducted in the spring of 2005 through in-home interviews, poses questions about current employment and collection of public benefits as income replacement. Furthermore, it covers work experience and expected retirement age for people still on the labor market and work experience and retirement reasons for those already retired. We have, moreover, included an array of questions concerning health and health status. All respondents underwent an audiometric hearing test after the survey interview was concluded.

In this study, only people on the labor market and receiving disability benefits are included, leaving us with a data set containing 1,990 respondents. That is to say, we exclude people on an early retirement scheme, people on sick leave, people enrolled in an educational program and housewives not working away from home. We choose to exclude people on an early retirement scheme because this form of exit from the labor market is voluntary whereas exit through disability benefits is most often involuntarily due to health problems and thereby constitute a very different reason for exiting.

\section{B. Measurement of hearing disability}

To capture hearing difficulties in the population as accurately as possible, we use two different ways of measuring hearing ability: a clinical audiometric hearing test for all respondents without the use of hearing aid and an assessment of the respondents' functional hearing in everyday life based on survey self-reports. To date, few studies about the hearing impaired have had access to data containing responses from both hearing impaired individuals and individuals with normal hearing. By using our own measurements of the respondents' hearing loss, we are able to record and compare labor force participation and work experience according to the severity of the hearing disability, ranging from people with no hearing difficulties to those with severe hearing problems. By using a combination of both self-reported hearing ability and the results of an audiometric hearing test, we are able to gain a better understanding of the effect of hearing disabilities on the application and allotment of disability benefits while also 
being able to detect and include people who are unaware of, or reluctant to acknowledge their hearing loss. In this way we hope to measure hearing more precisely, but at the same time, pay special heed to the compatibility of the two health measures and the econometric problems associated with applying these in labor supply and employment estimations. In the following sections we will describe the two different methods of hearing measurement and the different coping strategies included in the survey.

\section{The audiometric hearing test}

Sounds vary according to intensity measured in decibels $(\mathrm{dB})$ and frequency measured in hertz $(\mathrm{Hz})$. In pure tone audiometry, the hearing threshold in $\mathrm{dB}$ is measured for each ear at frequencies of different $\mathrm{Hz}$, varying from low pitch to high pitch. We have measured the respondents' hearing at 500, 1,000, 2,000 and 4,000 Hz, see Figure 1 for an audiogram for a typical individual in our sample. In order to classify the hearing level, we find the average hearing threshold across the different frequencies and use the average for the better ear. If there is more than a $25 \mathrm{~dB}$ difference between the average thresholds for the two ears, we add $5 \mathrm{~dB}$ to the average threshold for the better ear. This procedure is the standardized ISO method (ISO 1990). The measure has a range from $10 \mathrm{~dB}$ to $90 \mathrm{~dB}$. A $0 \mathrm{~dB}$ threshold average is considered to be normal hearing, a $45 \mathrm{~dB}$ threshold average as a moderate hearing disability, whereas a $\mathrm{dB}$ threshold average of 90 or more represents severe hearing problems. In Figure 1, the individual has a hearing threshold of $22.5 \mathrm{~dB}$ equivalent to a very mild hearing disability.

\section{FIGURE 1 ABOUT HERE}

Most people lose their hearing ability in the high frequencies first (Toh et al. 2002). Fifty percent of the information in normal speech lies within $1,600-4,000 \mathrm{~Hz}$ and 70 percent in the area above $1,000 \mathrm{~Hz}$. Therefore, being able to hear at high frequencies is very important for understanding speech. Because having good hearing in the low tones does not compensate for the loss of hearing in the high tones and because a $\mathrm{dB}$ threshold average ranging from low pitch to high pitch does not account for this factor (Pavlovic 1987), we use an average of the $\mathrm{dB}$ hearing level at only 2,000 and 4,000 $\mathrm{Hz}$ 
in our estimations. In terms of Figure 1, this would yield an average of $30 \mathrm{~dB}$ equivalent of a mild hearing disability. We believe that by so doing we obtain the most accurate picture of the populations' hearing abilities. The threshold average with measurements only at 2,000 and $4,000 \mathrm{~Hz}$ also seem to have the strongest correlation with receipt of disability benefits because it has a significant effect for women (see appendix A). This is caused by women generally having fewer hearing problems than men while they also set in later in life for women.

Although audiometric procedures such as pure tone audiometry provide information about the extent of hearing loss and sound sensitivity, these procedures do not necessarily reflect the various problems that people with a hearing impairment experience in daily life. Hearing problems can take on many forms, resulting not only from a lower sound sensitivity but also from perceptive or cognitive difficulties. Furthermore, a hearing loss can be experienced differently from person to person, and people may cope with it in different ways. Therefore, as self-reported health might capture real health more precisely than objective health measures, it becomes a useful supplement or alternative to the more objective clinically obtained measures such as pure tone audiometry. We therefore also include a measurement of the respondents' self-reported functional hearing in daily life.

\section{Functional hearing in daily life}

Self-reporting procedures have become a valuable tool for the assessment of auditory disability, because an understanding of how individuals feel about a hearing impairment, how they behave, and how they cope with problems resulting from hearing loss in real-world communication situations provide crucial information. On the other hand, self-reported measures are sometimes thought to be endogenous in labor supply estimations, because people might report poor health to, for example, justify collecting disability benefits. We have therefore chosen to include both the objective (i.e., clinically obtained) and the more subjective measurement of the respondents' hearing in our analyses.

We posed respondents six different questions about their daily life experiences with their hearing. The questions were: 1) "Do you find it difficult to hear someone who talks loudly in a quiet room?”, 2) "Do you find it difficult to hear someone who talks 
with a normal voice-level in a quiet room?”, 3) "Do you have difficulties following a conversation when there is background noise?”, 4) “Can you watch a television program on a volume acceptable for others?”, 5) “Are you able to hear a telephone or doorbell ring?” and 6) “Do you hear well enough to use a normal telephone?” We then constructed an index ranging from 0 to 6 , measuring the level of hearing difficulties in daily life, with the value of 0 representing no hearing problems and the value of 6 representing severe hearing problems.

For respondents with hearing aids, the clinically obtained audiometric hearing test and more objective component tested them without their hearing aids, whereas this selfreported and more subjective component allowed them to answer based on their experiences of hearing with their hearing aids.

Most people with a lowered hearing sensibility as measured in the audiometric hearing test will also be affected by their hearing loss in everyday life. We therefore see a significant correlation between the two measurements (Appendix B). However, we do see that some individuals do not seem to be affected in every day life by their lowered sound sensibility, whereas others seem to have problems with their hearing in everyday life even though we do not measure them as having a hearing loss in the audiometric hearing test. This underlines the importance of including both measurements in our estimations.

\section{Coping strategies}

In our survey, individuals who acknowledge their hearing problem are presented with different questions relating to coping. First, we ask if they have informed their employer about their disability, making it possible for the employer to relieve the effects of the hearing problem at work. Second, we ask about availability of assistive devices such as wire loops, phone amplifiers, text phones, or interpreters at work. The hypothesis is that the use of these coping strategies will affect labor market attachment given that they can ease some of the hearing problems experienced at the work place. However, they do not influence measured functional hearing as the coping strategies included here do not affect daily life experiences. Having a hearing aid is not considered as a coping strategy as it will affect functional hearing. 


\section{Estimation}

\section{A. The basic model for estimation of receipt of disability benefits}

As our first research question we wish to examine to what extent hearing difficulties influence early retirement through disability benefits. About 7.5 percent of the Danish population between the age of 18 and 67 years receive disability benefits. Disability benefits can be granted to people who cannot work or support themselves because of physical, psychological, or social reasons. When granting disability benefits, the applicant's working capacity is evaluated in regard to their physical resources, the possibility of improvement of the condition, and any barriers faced on the labor market. An applicant's working capacity has to be permanently reduced and to an extent that he or she would not be able to hold a job or be self-supporting no matter the kind of support or aid offered on the job. The recipient of disability benefits is only allowed to have very limited labor income in addition to the disability benefits and is therefore in reality no longer a part of the work force (Ministry of Social Affairs 2002).

However, receipt of disability benefits is the result of two processes. First, the decision to apply by the individual and second, the allotment by the Danish system.

$$
P R O P(d)=P R O P(\text { ALOT } \mid \text { application }) * P R O P(\text { application })
$$

We hypothesize that having hearing difficulties will increase the probability of applying for disability benefits because of the difficulties experienced at the work place. Hearing problems in themselves will not increase the probability of allotment of disability benefits. When applying for disability benefits on the grounds of a hearing disability, a medical diagnosis of the hearing impairment will be required. Although a hearing disability will seldom be grounds enough in itself for granting disability benefits, hearing problems in conjunction with other health or social problems can, however, contribute to a diagnosis of overall reduced working capacity sufficient to keep the individual out of the labor force.

We denote receipt of disability benefits, $d$, and hearing impairment measurements $c$ and $f$ for the clinically obtained hearing test measurement and functional measurement respectively. If functional impairment $f$ is measured perfectly, we should not expect the audiometric hearing test results $c$ to have a strong impact on early 
retirement through disability benefits, $d$. To test this assumption our first model only includes the effect of a functional hearing disability on receipt of disability benefits leaving out the clinically measured hearing level. The vector $x$ is a vector of personal characteristics such as age, health, and educational background, while $e$ is the residual representing any unobserved factors. If functional hearing is exogenous then $\beta_{f} f$ can be interpreted as a consistent estimate of the true effect of a hearing disability on the receipt of disability benefits.

$$
d=\beta_{f} f+\beta_{x} x+e
$$

In practice, however, $c$ might affect $d$ due to any divergence between the two measurements. Equation II therefore shows our expanded model of the effect of a hearing impairment on receipt of disability benefits.

$$
d=\beta_{f} f+\beta_{c} c+\beta_{c h} c h+\beta_{x} x+e
$$

Previous research has shown a connection between health problems and hearing problems. People, who suffer from hearing problems, find their health problems more burdensome than do normal hearing people (Lee et al. 2005; Dalton et al. 2003; Crandell et al. 2003; Pope \& Sowers 2000; Appollonio et al. 1995). This interaction is supported by the fact that certain medications prescribed to cure specific health problems can cause hearing problems as a side effect. We have therefore chosen to include an interaction effect between the clinically measured hearing and other health problems, $c h$.

We conduct the analysis separately for men and women: Firstly, because retirement patterns differ for men and women, with women retiring one year earlier than men on average (Ministry of Employment et al. 2003), secondly, because of the gender differences in the prevalence and severity of hearing difficulties, and thirdly, because men and women are affected by their hearing problems in different ways and tend to use different coping strategies. 


\section{B. Endogenous functional hearing}

The analysis of the impact of a functional hearing disability on receipt of disability benefits raises the question of endogeneity. The self-reported measure can be endogenous because individuals may report hearing loss, e.g to justify collecting disability benefits even though only very few respondents in this study report that their hearing problems have caused or affected their exit from the labor market. We therefore supplement model II by estimating a linear simultaneous model of receipt of disability benefits and functional hearing, accounting for the possible endogeneity of the functional hearing measure. This leads us to the following model:

$$
\begin{aligned}
& d=\beta_{f} f+\beta_{c} c+\beta_{c h} c h+\beta_{x} x+e \\
& f=\gamma_{c} c+\gamma_{x} x+\gamma_{a} a+\gamma_{s} s+u
\end{aligned}
$$

This model is identified by the assumption that possession of a hearing aid, $a$, and age*age, $s$, is not correlated with disability exit, $d$. Thus, we propose the possession of a hearing aid and age*age as instruments in order to obtain the casual effect of a hearing impairment on receipt of disability benefits.

Possession of a hearing aid does not depend on income as it is granted free of charge by the Danish Government to all people with a hearing loss irrespective of income or status on the labor market (National Board of Health 2007). When applying for disability benefits on the grounds of reduced hearing or hearing difficulties, the applicant is required to undergo a medical examination i.e., having his or her hearing tested by an audiologist. The hearing tests are performed without the use of an hearing aid, making possession of a hearing aid irrelevant for the measured level of hearing difficulties in the hearing test and thereby the granting of disability benefits (Ministry of Social Affairs 2006; Ministry of Employment 2002a, 2002b). We can also assume that people who apply for disability benefits on the grounds of a hearing disability already are aware of their hearing loss and have acted upon it - otherwise they would not use it as a reason for applying. Receipt of disability benefits will therefore not influence possession of a hearing aid making it a valid instrument in our estimations. Use of a hearing aid does however relieve the hearing difficulties, i.e. it has an effect on the functional hearing, $f$. 
Hearing loss prevalence and severity increase steadily with age, but escalates sharply at about age 55 (Ries 1994). Therefore, age*age might give a better estimate of the correlation between age and functional hearing than the linear measurement of age. Even thought receipt of disability benefits also increases with age, a dramatic increase is not to be expected. Starting at age 60, most individuals have the possibility of going on early retirement benefits and will therefore choose this over disability benefits if possible. We therefore do not see the same a sharp escalation of receipt of disability benefits with age as in the case of functional hearing problems. Age*age should therefore not influence receipt of disability pension.

The vector $x$ is a vector of the personal characteristics influencing both receipt of disability benefits and functional hearing i.e. age. Clinically measured impairment, $c$, is thought to affect both receipt of disability benefits and functional hearing. The model also allows for correlations between error terms $e$ and $u$.

\section{Coping Strategies}

Not only the level of hearing problems, but also the ways in which the hearing impaired cope with their problem may influence labor force participation and receipt of disability benefits. We therefore address the question of coping strategies and their influence on receipt of disability benefits. The coping strategies included are: informing one's employer and the use of assistive devices. We denote the two coping strategies $i^{e}$ and $m$, respectively and include them in the model. As informing the employer is potentially endogenous - because the hearing impaired employee might tell his or her employer about the hearing difficulties when applying for the disability benefits - we instrument it by whether or not hearing impaired respondents usually instruct surrounding persons how best to communicate in order for the hearing impaired to follow the conversation in the best way possible, $i^{s}$, and by years lived with a hearing loss, $w$. We furthermore include functional hearing, $f$, personal characteristics, $x$, and use of assistive aids at the work place, $m$, in the equation. Leading us to the following model:

$$
\begin{aligned}
& d=\beta_{f} f+\beta_{c} c+\beta_{c h} c h+\beta_{x} x+\beta_{i^{e}} i^{e}+\beta_{m} m+e \\
& f=\gamma_{c} c+\gamma_{x} x+\gamma_{a} a+\gamma_{s} s+u \\
& i^{e}=p_{f} f+p_{x} x+p_{i} i^{s}+p_{m} m+p_{w} w+v
\end{aligned}
$$


This model is identified by the assumption that the strategy of instructing one's social surroundings in the best way of communicating and number of years with hearing loss is correlated with informing employers, but not with functional hearing or the receipt of disability benefits.

We assume that some individuals are more open about talking about their hearing difficulties whether to their social surroundings or to their employer. They have acknowledged their reduced hearing capacity, they have acted upon it, and they try to relieve its consequences. In contrast, others may feel reluctant to talk about their hearing impairment and will therefore probably also be apprehensive about telling their employer about the hearing problems. These individuals might not have acknowledged their reduced hearing level, or they are afraid of being labeled because of it. Even though the act of instructing others may be a way to improve functional hearing in some situations, it will not affect the measurement of functional hearing used in this analysis. The six questions that constitute the aggregated measurement of functional hearing all focus on often-experienced situations not subject to individual coping strategies. Being able to hear a telephone or doorbell ring, watch a television program at a volume acceptable for others, or being able to hear someone who talks loudly in a quiet room are all everyday situations encountered by us all. Respondents should therefore have answered these questions from their everyday experiences and not from situations where friends are asked to speak louder or more clearly for the hearing impaired to be able to hear them. Receipt of disability benefits should not be correlated with this type of communication strategy because it refers to a general way of coping with one’s hearing disability unrelated to one’s work life or labor market attachment.

We furthermore presume that individuals who have lived several years with their hearing loss will be more open about it and more often have acknowledged it than individuals with a recent hearing loss. Again, years lived with a hearing loss should not be correlated with functional hearing as the measurement refers to commonly experienced situations affected by actual hearing ability irrespective of how long the hearing loss have been present. And it should not be correlated with receipt of disability pension which should depend solely on the hearing ability at the time of application.

Possession of a hearing aid, $a$, should not be correlated with telling the employer, $i^{e}$. One the one hand, one might think that people with a hearing aid will be more inclined 
towards telling their employer about their hearing problems because they carry a visible symbol of them. On the other hand, research show that hearing aid users are less inclined towards using alternative coping strategies such as openness about their hearing disability and instead rely solely on their hearing aid for relief (Cox et al. 2005). Furthermore, we do not know if people in possession of a hearing aid actually use it at their work place given that many individuals owning a hearing aid do not use it all the time but instead only use it occasionally (Smeeth et al. 2002) and, when they do, it will most often be in the private sphere where they feel the most disabled by their hearing problems (Hallberg 1996; Hétu et al. 1993).

The model allows for correlations between error terms $e, u$ and $v$. In all our estimations, we account for survey response filtering, since people who do not have or do not acknowledge their hearing difficulties are not asked about their coping strategies. The systems of linear simultaneous equations in (III) and (IV) are estimated via maximum likelihood using PROC CALIS in SAS.

\section{Estimation results}

In this section, we present the results from our analyses: that is 1) the estimated effect of a hearing impairment on receipt of disability benefits and 2) the effect of using different coping strategies. Table 1 shows the estimation results for men and table 2 the results for women.

\section{A. The effect of a hearing impairment on receipt of disability benefits}

In all four estimation models poor health significantly increases the probability of receiving disability benefits for both males and females by about 5-7 percentage points (linear probability). This correlation is of course not very surprising since disability benefits are granted on the basis of disabling health problems.

According to the results from the first model, in which receipt of disability benefits is explained only by self-reported functional hearing and other individual characteristics as in the previous literature, a hearing disability does have a statistically significant effect on receipt of disability benefits for both genders, raising the chances of exit by 
about 8 percentage points for men and 7 percentage points for women. This result changes in the following models.

Comparing models II and III, accounting for endogeneity reduces the estimated parameter from 8.8 to 6.3 percentage points for men while the estimated effect is unchanged for women. Thus, endogeneity bias is more severe for men than women. For men, the effect of functional hearing was biased upwards, , suggesting that hearing problems may be used as a sort of rationalization by men on disability benefits which is not the case for women. The comparison of model II to model III is interesting because we identify the more policy-relevant local average treatment effect, or LATE, of a hearing problem in III by way of the compliers (those whose functional hearing difficulties were improved by the use of a hearing aid) and this effect is different from the average treatment effect estimated in model II. Including coping strategies in model IV, not unexpectedly, reduces the negative effect of functional hearing on disability exit to 5 percentage points for men and 3.5 percentage points for women.

The results differ somewhat between the two genders when it comes to the effect from a clinically measured hearing impairment. Where a functional hearing disability affects receipt of disability benefits, a clinically measured hearing disability does not have an effect for men. Other controls show the expected effects - age significantly increases the odds of disability exit, higher levels of education relative to basic education lower it, as does white-collar work relative to blue-collar work.

Our instrument - having a hearing aid - is found to be significantly positively related to functional hearing problems with a t-value of 4.32 for men.

We see somewhat different results for women. On the one hand a functional hearing disability significantly affects receipt of disability benefits and increase women's likelihood of receiving disability benefits by 3.5 percentage points. On the other hand, a clinically measured hearing impairment in itself decreases women's likelihood of receiving disability benefits. A clinically measured hearing impairment in combination with other health problems does nevertheless still increase the likelihood by 0.09 percentage points for every $1 \mathrm{~dB}$ increase accompanied by health problems (on a base of $17.8 \mathrm{~dB}$ ). Therefore a woman with e.g. 2 health problems will increase her probability of being on disability benefits with 1.8 percentage point for every $10 \mathrm{~dB}$ she gains in average hearing threshold. Given that most women (and men) with a clinically 
measured hearing impairment will also be functionally affected by it in their everyday life, the overall picture of the hearing abilities effect on receipt of disability benefits is still an increase in the probability of being on disability benefits. As a clinically measured hearing impairment in connection with other types of health problems also has a negative impact on labor market attachment for women, we can conclude that only for women with no other health problems and who are not functionally affected by their hearing problems does a clinically measured hearing impairment decrease the possibility of being on disability benefits. This result underscores the difficulties of being granted disability benefits on the grounds of hearing problems alone without other accompanying health issues, along with the fact that women without functional hearing problems or other types of health problems will not apply for disability benefits. As found for men, older women and women with poorer health are significantly more likely to receive disability benefits, as are women with basic education compared to other educational groups, and women holding blue-collar jobs. Privately employed women are likewise more likely to receive disability benefits than publicly employed women.

Also here, the instrument we employ, possession of a hearing aid, is significantly positively related to functional hearing problems with a t-value of 4.7.

Our previous supposition thus seems to be verified for both men and women. Having functional hearing problems will increase the probability of receiving disability benefits. However, the hearing impairment in itself does not seem to increase the probability of receiving disability benefits, given that the clinically measured hearing level in it self does not influence the probability of receiving disability benefits. It thus seems that an unacknowledged hearing impairment will not increase the probability of being on disability benefits, the main effect is through the functional hearing and hearing difficulties experienced in everyday life. Furthermore, there seems to be evidence for the hypothesis that having hearing problems will increase the likelihood of applying for disability benefits, while it does not increase the likelihood of being granted disability benefits. 


\section{B. Coping Strategies}

As our second research question, we examine the effects on labor supply of using the two different coping strategies of informing one's employer about the hearing problem and using different assistive devices at work. Because we account for the survey response filtering, these effects are estimated only based on those individuals with a hearing loss.

A positive finding seems to be that the use of assistive devices at the work place significantly decreases the likelihood of receiving disability benefits by 20.5 percentage points for men. However, men who inform their employer about the hearing disability increase their likelihood of being on disability benefits by 6.6 percentage points. The instrument (instructing one's social surroundings) is significantly positively related to telling the employer about the hearing problem with a t-value of 4.18. Also number of years with hearing loss is significantly positively related to telling the employer with a t-value of 5.26.

Turning to the results for women, we see a similar picture. The use of assistive aids at work lower women's probability of being on disability benefits with 32.5 percentage points - somewhat more than for men. As women's jobs (typically as school teachers or nurses in the public sector in the very segregated labor market in Denmark) rely more on communication skills, having assistive aids at work may increase their productivity differentially more than men's and may therefore explain the stronger effect on reducing their disability exit.

As is the case for men, women who inform their employer about their hearing difficulties have a higher probability of leaving the labor market. The effect is highly significant and rather large with an increase by 36.8 percentage points. Interestingly, the instrument - instruction of others in the best communication strategy - is estimated to be negatively related to telling the employer, although significant (t-value -4.96). Number of years with hearing loss is significantly positively related to telling the employer with a t-value of 15.86 . Women thus seem to make a distinction between their general communication strategies and their employer relations as opposed to men. Validating this result, previous research indicates that men and women have varying patterns of interaction and network differently at the work place with men more often 
interacting and participating in networks with co-workers of higher positions as e.g. managers and supervisors (Hultin \& Szulkin 1999; Ibarra 1993; Brass 1985).

As the number of excluded instruments exceeds the number of endogenous variables in the system, a problem of overidentification is potentially present. To explore whether this is an issue, we present the estimated coefficients on the endogenous variables excluding each of the instruments in turn. The results are shown in Appendices D and E. We find that the estimated effect of functional hearing on disability exit is positive and significant and unaffected by whether respectively age*age or hearing aid is excluded. The coefficient on informing the employer is positive and highly significant for both men and women under each of the instrument configurations, although the effect is larger for men when Years with loss is excluded and larger for women when Instruction is excluded. Still, the gender difference mentioned earlier is present in all cases and shows that telling the employer raises women's probability of disability exit considerably more than it does men's. 
Table 1. Estimates for receipt of disability benefits for men

\begin{tabular}{|c|c|c|c|c|}
\hline & Model I & Model II & Model III & Model IV \\
\hline \multicolumn{5}{|l|}{ Disability benefits } \\
\hline Intercept & $-0.018(-0.93)$ & $-0.027(-1.19)$ & $-0.024(-1.08)$ & $-0.041(-1.84)^{*}$ \\
\hline Age 50-64 & $0.010(7.36) * * *$ & $0.011(8.08)^{* * *}$ & $0.011(8.04)^{* * *}$ & $0.013(9.16)^{* * *}$ \\
\hline Basic general edu. & Reference & Reference & Reference & Reference \\
\hline Upper secondary level & $-0.044(-1.03)$ & $-0.062(-1.45)$ & $-0.060(-1.41)$ & $-0.054(-1.26)$ \\
\hline Vocational & $-0.101(-6.66)^{* * *}$ & $-0.112(-7.31)^{* * *}$ & $-0.114(-7.43)^{* * *}$ & $-0.101(-6.47)^{* * *}$ \\
\hline Short-cycle higher & $-0.066(-2.57)^{* * *}$ & $-0.082(-3.21)^{* * *}$ & $-0.080(-3.14)^{* * *}$ & $-0.075(-2.81)^{* * *}$ \\
\hline Medium-cycle higher & $-0.050(-2.46)^{* *}$ & $-0.061(-2.95) * * *$ & $-0.062(-3.02) * * *$ & $-0.040(-1.93)^{*}$ \\
\hline Long-cycle higher & $-0.038(-1.77)^{*}$ & $-0.051(-2.38)^{* *}$ & $-0.052(-2.40)^{* *}$ & $-0.042(-1.98)^{* *}$ \\
\hline Blue-collar job & Reference & Reference & Reference & Reference \\
\hline White-collar job & $-0.061(-4.89) * * *$ & $-0.052(-4.12)^{* * *}$ & $-0.054(-4.28)^{* * *}$ & $-0.063(-5.01)^{* * *}$ \\
\hline Privately employed & Reference & Reference & Reference & Reference \\
\hline Publicly employed & $0.000(0.01)$ & $-0.005(-0.43)$ & $-0.005(-0.41)$ & $-0.009(-0.76)$ \\
\hline Health $^{\mathrm{a}}$ & $0.068(24.17)^{* * *}$ & $0.070(13.43)^{* * *}$ & $0.071(13.56)^{* * *}$ & $0.070(13.30)^{* * *}$ \\
\hline Functional hearing & $0.081(6.93)^{* * *}$ & $0.088(7.06)^{* * *}$ & $0.063(4.31)^{* * *}$ & $0.050(3.42)^{* * *}$ \\
\hline Clinical hearing ${ }^{\mathrm{b}}$ & & $0.015(0.31)$ & $0.033(0.69)$ & $0.030(0.61)$ \\
\hline Clinical hearing*health & & $-0.008(-0.60)$ & $-0.007(-0.50)$ & $-0.013(-0.93)$ \\
\hline Informed employer & & & & $0.066(3.08)^{* * *}$ \\
\hline Assistive aids & & & & $-0.205(-4.54) * * *$ \\
\hline \multicolumn{5}{|l|}{ Functional hearing } \\
\hline Intercept & & & $0.211(2.52)^{* * *}$ & $0.261(3.45)^{* * *}$ \\
\hline Hearing aid & & & $0.129(3.41)^{* * *}$ & $0.276(8.26)^{* * *}$ \\
\hline Clinical hearing & & & $0.558(5.39) * * *$ & $0.376(4.32)^{* * *}$ \\
\hline Age 50-64 & & & $0.012(0.63)$ & $-0.016(-1.04)$ \\
\hline Age*age & & & $-0.002(-1.45)$ & $0.000(0.42)$ \\
\hline Health & & & $0.086(11.91)^{* * *}$ & $0.090(13.03)^{* * *}$ \\
\hline Basic general edu. & & & Reference & Reference \\
\hline Upper secondary level & & & $0.249(2.08)^{* *}$ & $0.217(1.89)^{*}$ \\
\hline Vocational & & & $-0.249(-5.46)^{* * *}$ & $-0.224(-5.18)^{* * *}$ \\
\hline Short-cycle higher & & & $0.037(0.56)$ & $0.319(4.66) * * *$ \\
\hline Medium-cycle higher & & & $-0.218(-3.63)^{* * *}$ & $-0.169(-2.86)^{* * *}$ \\
\hline Long-cycle higher & & & $0.021(0.32)$ & $0.095(1.55)$ \\
\hline Blue-collar job & & & Reference & Reference \\
\hline White-collar job & & & $0.028(0.73)$ & $0.006(0.16)$ \\
\hline Privately employed & & & Reference & Reference \\
\hline Publicly employed & & & $0.038(1.09)$ & $0.042(1.24)$ \\
\hline \multicolumn{5}{|l|}{ Informed employer } \\
\hline Intercept & & & & $0.033(0.40)$ \\
\hline Instruction & & & & $0.133(4.18)^{* * *}$ \\
\hline Functional hearing & & & & $0.727(7.11)^{* * *}$ \\
\hline Years w. hearing loss & & & & $0.006(5.26)^{* * *}$ \\
\hline Assistive aids & & & & $-0.004(-0.07)$ \\
\hline Age 50-64 & & & & $0.011(2.24)^{* *}$ \\
\hline Basic general edu. & & & & Reference \\
\hline Upper secondary level & & & & $-0.247(-1.75)^{*}$ \\
\hline Vocational & & & & $0.214(3.77)^{* * *}$ \\
\hline Short-cycle higher & & & & $-0.192(-2.29)^{* *}$ \\
\hline Medium-cycle higher & & & & $-0.080(-1.07)$ \\
\hline Long-cycle higher & & & & $-0.184(-2.54)^{* * *}$ \\
\hline Blue-collar job & & & & Reference \\
\hline White-collar job & & & & $-0.092(-2.12)^{* *}$ \\
\hline
\end{tabular}




\begin{tabular}{|l|l|l|l|l|}
\hline Privately employed & & & \\
\hline Publicly employed & & & Reference \\
\hline $\begin{array}{l}\text { Goodness of fit index } \\
\text { adjusted for d.o.f. (AGFI) }\end{array}$ & 0.9565 & 0.9243 & 0.9274 & $0.064(1.55)$ \\
\hline Chi-sq,Prob>chi chi $110.64,=0.0690$ & $197.27,<.0001$ & $241.55,<.0001$ & $547.90,<.0001$ \\
\hline
\end{tabular}

T-test statistics in parenthesis. Significance level: * at 10 percent, $* *$ at 5 percent, *** at 1 percent a. Scale from 1-10 concerning different health problems. b. Estimates for clinical hearing and clinical hearing*health are multiplied by 100 .

Table 2. Estimates for receipt of disability benefits for women

\begin{tabular}{|c|c|c|c|c|}
\hline & Model I & Model II & Model III & Model IV \\
\hline \multicolumn{5}{|l|}{ Disability benefits } \\
\hline Intercept & $-0.014(-0.682)$ & $0.042(1.73)^{*}$ & $-0.067(-2.47)^{* *}$ & $0.006(0.21)$ \\
\hline Age 50-64 & $0.012(7.88)^{* * * *}$ & $0.010(6.53) * * *$ & $0.022(12.00)^{* * * *}$ & $0.023(12.17)^{* * *}$ \\
\hline Basic general edu. & Reference & Reference & Reference & Reference \\
\hline Upper secondary level & $-0.087(-1.82)^{*}$ & $-0.080(-1.71)^{*}$ & $-0.205(-3.66)^{* * *}$ & $-0.182(-3.15)^{* * *}$ \\
\hline Vocational & $-0.062(-3.63)^{* * *}$ & $-0.062(-3.70)^{* * *}$ & $-0.060(-3.07)^{* * *}$ & $-0.064(-3.09) * * *$ \\
\hline Short-cycle higher & $-0.047(-2.22)^{* *}$ & $-0.055(-2.61)^{* * *}$ & $-0.037(-1.48)$ & $-0.041(-1.57)$ \\
\hline Medium-cycle higher & $-0.045(-2.24) * *$ & $-0.047(-2.38)^{* *}$ & $-0.061(-2.67)^{* * *}$ & $-0.083(-3.51)^{* * *}$ \\
\hline Long-cycle higher & $-0.063(-2.36)^{* *}$ & $-0.058(-2.17)^{* *}$ & $-0.003(-0.11)$ & $-0.043(-1.29)$ \\
\hline Blue-collar job & Reference & Reference & Reference & Reference \\
\hline White-collar job & $-0.074(-4.72)^{* * * *}$ & $-0.071(-4.65)^{* * *}$ & $-0.105(-5.69) * * *$ & $-0.079(-4.15)^{* * *}$ \\
\hline Privately employed & Reference & Reference & Reference & Reference \\
\hline Publicly employed & $0.000(0.02)$ & $-0.001(-0.07)$ & $-0.018(-1.33)$ & $-0.061(-4.22) * * *$ \\
\hline Health $^{\mathrm{a}}$ & $0.053(17.87)^{* * *}$ & $0.023(4.25)^{* * *}$ & $0.058(9.56)^{* * *}$ & $0.056(8.99)^{* * *}$ \\
\hline Functional hearing & $0.073(4.59)^{* * *}$ & $0.051(3.16)^{* * *}$ & $0.052(2.85)^{* * *}$ & $0.035(1.82)^{*}$ \\
\hline Clinical hearing ${ }^{\mathrm{b}}$ & & $-0.216(-2.64)^{* * *}$ & $0.156(2.11)^{* *}$ & $-0.335(-4.04)^{* * *}$ \\
\hline Clinical hearing*health & & $0.151(6.18)^{* * *}$ & $0.053(2.39)^{* *}$ & $0.085(3.77)^{* * * *}$ \\
\hline Informed employer & & & & $0.368(11.61)^{* * *}$ \\
\hline Assistive aids & & & & $-0.325(-4.48)^{* * *}$ \\
\hline \multicolumn{5}{|l|}{ Functional hearing } \\
\hline Intercept & & & $1.092(9.87)^{* * *}$ & $0.697(9.76)^{* * * *}$ \\
\hline Hearing aid & & & $0.236(4.34)^{* * *}$ & $0.115(4.72)^{* * *}$ \\
\hline Clinical hearing & & & $0.544(4.13)^{* * *}$ & $0.765(8.65)^{* * *}$ \\
\hline Age 50-64 & & & $-0.126(-5.22)^{* * *}$ & $-0.073(-5.85) * * *$ \\
\hline Age*age & & & $0.007(4.98)^{* * *}$ & $0.004(6.32)^{* * *}$ \\
\hline Health & & & $-0.020(-2.22)^{* *}$ & $0.008(0.96)$ \\
\hline Basic general edu. & & & Reference & Reference \\
\hline Upper secondary level & & & $0.275(2.39)^{* *}$ & $0.249(2.26)^{* *}$ \\
\hline Vocational & & & $0.003(0.06)$ & $0.099(1.83)^{*}$ \\
\hline Short-cycle higher & & & $-0.193(-2.29)^{* *}$ & $-0.257(-2.90)^{* * *}$ \\
\hline Medium-cycle higher & & & $-0.143(-2.40)^{* *}$ & $-0.066(-1.03)$ \\
\hline Long-cycle higher & & & $-0.070(-0.96)$ & $0.202(2.46)^{* *}$ \\
\hline Blue-collar job & & & Reference & Reference \\
\hline White-collar job & & & $-0.052(-0.90)$ & $-0.081(-1.41)$ \\
\hline Privately employed & & & Reference & Reference \\
\hline Publicly employed & & & $-0.204(-5.85) * * *$ & $-0.239(-7.07)^{* * *}$ \\
\hline \multicolumn{5}{|l|}{ Informed employer } \\
\hline Intercept & & & & $-0.475(-3.20)^{* * *}$ \\
\hline Instruction & & & & $-0.126(-4.96)^{* * *}$ \\
\hline Functional hearing & & & & $1.671(10.07)$ \\
\hline
\end{tabular}




\begin{tabular}{|l|l|l|l|l|}
\hline Years w. hearing loss & & & & $0.017(15.86)^{* * *}$ \\
\hline Assistive aids & & & & $0.461(6.50)^{* * *}$ \\
\hline Age 50-64 & & & & $-0.000(-0.05)$ \\
\hline Basic general edu. & & & & Reference \\
\hline Upper secondary level & & & & $-1.241(-6.33)^{* * *}$ \\
\hline Vocational & & & & $-0.204(-2.13)^{* *}$ \\
\hline Short-cycle higher & & & & $0.102(0.71)$ \\
\hline Medium-cycle higher & & & & $-0.243(-2.20)^{* *}$ \\
\hline Long-cycle higher & & & & $-1.235(-7.77)^{* * *}$ \\
\hline Blue-collar job & & & & Reference \\
\hline White-collar job & & & & $0.201(1.92)^{*}$ \\
\hline Privately employed & & & Reference \\
\hline Publicly employed & & & $0.569(7.36)^{* * *}$ \\
\hline $\begin{array}{l}\text { Goodness of fit index } \\
\text { adjusted for d.o.f. (AGFI) }\end{array}$ & 0.5390 & & 0.9328 & 0.8386 \\
\hline Chi-sq,Prob> chi & $2109.45,<.0001$ & $2128.98,<.0001$ & $200.91,=.0005$ & $626.95,<.0001$ \\
\hline
\end{tabular}

T-test statistics in parenthesis. Significance level: $*$ at 10 percent, $* *$ at 5 percent, $* * *$ at 1 percent.

a. Scale from 1-10 concerning different health problems. b. Estimates for clinical hearing and clinical hearing*health are multiplied by 100 .

\section{Conclusion}

With large numbers of people being affected by hearing difficulties and an expected increase in future years, estimations of the way this specific disability affects labor supply is not only important on an individual level for the hearing disabled but on a societal level as well. We conclude that people with a hearing disability have a higher probability of leaving the labor market and receiving disability benefits than people without hearing difficulties. Through the use of two different measurements of hearing abilities we conclude that functional hearing abilities play the largest role in exit from the labor market as opposed to the more objective clinically measured hearing abilities - i.e. experienced hearing difficulties are the most important. Furthermore, it seems that hearing problems most likely increase the probability of applying for disability benefits whereas the probability of being granted disability benefits are not affected at the same rate.

However, there are some gender differences in the results. We see similar results concerning the effects of hearing problems on receipt of disability benefits, but some differences when it comes to the use of coping strategies. Both genders - women a bit more than men - succeed in lowering their probability of receiving disability benefits when they use assistive devices at the work place. In contrast, telling the employer about their hearing difficulties has a clear negative impact on labor market participation 
for both men and women, but the impact is greater for women with an increased probability of exit of 36.8 percentage points for women and 6.6 percentage points for men. Furthermore, this gender difference arises even after controlling for some characteristics of the individual's work i.e. sector and collar.

There may be a number of explanations for this gender difference. First of all, it might be that women with hearing difficulties are discriminated against to a greater degree than men. When women become hearing impaired, they may be more stigmatized and valued less by their employer and colleagues forcing them out of the labor market via disability benefits. On the other hand, the explanation might be that women rely more on their hearing and communicative skills than men do (Hallberg 1999). When their ability to communicate freely is affected, they become unsatisfied with their work ability and work life, and are more apt to want to retire from the labor market themselves.

Despite the positive news that hearing impaired persons who use assistive devices at the work place increase their chances of remaining on the labor market, it does not alter the result that having hearing difficulties increases the probability of receiving disability benefits for both men and women. People who tell their employer about the hearing difficulties are likewise more likely to receive disability benefits, making this an area of great importance for future research and action. 


\section{References}

Access Economics. 2006. Listen Hear! The economic impact and cost of hearing loss in Australia.

Appollonio, Ildebrando, Corrado Carabellese, Eugenio Magni, Lodovico Frattola, and Marco Trabucchi. 1995. "Sensory Impairmants and Mortality in an Elderly Community Population: A Six-year Follow-up Study.” Age and Aging vol. 24, No. 1: 30--36.

Bess, F., , M.J. Lichtenstein, M. Logan, and M.C. Burger. 1989. "Comparing criteria of hearing impairment in the elderly: A functional approach.” Journal of Speech and Hearing Research 32: 795--802.

Brass, Daniel J. 1985. “Men’s and Women’s Networks: A study of Interaction Patterns and Influence in an Organization.” The Academy of Management Journal, vol. 28, no. 2: $327-343$.

Brooks, H.C. and G.J. Ellis. 1982. "Self-esteem of hearing-impaired adolescents Effects of labelling.” YOUTH \& SOCIETY 14: 59--80.

Christensen, Vibeke T. 2006. Hard of Hearing? Hearing problems and working life. Copenhagen: The Danish National Institute of Social Research, report 06:35

Cox, M.C., G.C. Alexander, and G.A. Gray 2005. "Who Wants a Hearing Aid?

Personality Profiles of Hearing Aid Seekers.” Ear \& Hearing vol. 26, no. 1:12--26

Crandell, C. 1998. "Hearing aids: Their effects on functional health status.” The Hearing Journal 51: 22--30.

Crandell, C., S.M. Lewis, M. Valente, J. Enrietto, B.M. Kreisman, and N.V. Kreisman. 2003. Functional Health Benefits of Hearing Aid and FM Systems. In: Fabry, D.A. and D. DeConde Johnson. (ed.) 2003. ACCESS: Achieving Clear Communication Employing Sound Solutions 2003. Warrenville, Illinois: Phonak.: 53--59.

Dalton, Dayna S., Karen J. Cruickshanks, Barbara E.K. Klein, Ronald Klein, Terry L. Wiley, and David M. Nondahl. 2003. "The Impact of Hearing Loss on Quality of Life in Older Adults.” The Gerontologist 43: 661--668.

Danermark, B.D. 1998. "Hearing Impairment, Emotions and Audiological

Rehabilitation: a Sociological Perspective.” Scandinavian Audiology 27 supplement 49: 125--131.

Duijvestijn, Jan A., Lucien J.C Anteunis,. Jacques J.T. Hendirks, and Johannes J. Manni. 1999. "Defenition of Hearing Impairment and its Effect on Prevalence Figures". Acta Otolaryngol 119: 420--423. 
Fligor, B.J.and L.C. Cox. 2004. "Output Levels of Commercially Available Portable Compact Disc Players and the Potential Risk to Hearing.” Ear \& Hearing. 25(6):513-527

Garstecki, Dean C. and Susan F. Erler. 1998. "Hearing Loss, Control, and Demographic Factors Influencing Hearing Aid Use Among Older Adults”. Journal of Speech, Language, and Hearing Research 41: 527--537.

Goffman, Ervin. 1964. Stigma - Notes on the management of spoiled identity.

Englewood Cliffs, N.J.: Prentice-Hall.

Goffman, Ervin. 1959. The presentation of self in everyday life. Garden City, New York: Doubleday

Hallberg, Lillemor R.M. 1992. Hearing impairment, coping and perceived handicap In middle-aged individuals with acquired hearing loss: An interactional perspective. Göteborg: Psykologiska Institutionen, Göteborgs Universitet.

Hallberg, Lillemor R.M. 1996. “Occupational hearing loss: coping and family life.” Scandinavian Audiology vol 25, supplementum 43: 25-33.

Hallberg, Lillemor R.M. 1999. "Is there a gender difference in coping, perceived disability and handicap in patients with noise-induced hearing loss?” Noise \& Health 2:, 66--72

Hétu, Raymond. 1996. “The Stigma Attached to Hearing Impairment.” Scandinavian Audiology 25 (suppl 43): 12--24.

Hétu, R., L. Jones, and L. Getty. 1993. "The Impact of acquired hearing impairment on intimate relationships: implications for rehabilitation.” Audiology vol.32, no.6: 363381.

Hétu, R., L. Riverin, L. Getty, N.M. Lalande and C. St-Cyr. 1990. "The reluctance to acknowledge hearing difficulties among hearing-impaired workers.” British journal of Audiology, 24: 265--276.

HRF. 2005. Sanning och konsekvens - om hörselskadades situation i Sverige. Arsrapport 2005. http://www.hrf.se/upload/pdf/statistik/arsrapport2005.pdf

Hultin, Mia and Ryszard Szulkin. 1999. "Wages and Unequal Access to Organizational Power: An Empirical Test of gender Discrimination.” Administrative Science Quarterly vol. 44, no. 3: 453--472.

Ibarra, Herminia. 1993. "Personal Networks of Women and Minorities in Management: A Conceptual Framework.” The Academy of Management Review vol. 18, no.1: 56--87.

ISO. International Organization for Standardization. 1990. ISO Standards Handbook 35 Acoustics. Genève: International Organization for Standardization. 
Lee, David J., Byron L. Lam, Orlando Gómez-Marín, Diane Zheng, and Alberto J. Caban. 2005. "Concurrent Hearing and Visual Impairment and Morbidity in Community-Residing adults: the National Health Interview Survey, 1986 to1996.” Journal of Aging and Health vol. 17 No.5: 531--546.

Kochkin, Sergei. 2005. The impact of Untreated hearing Loss on Household Income. Better hearing Institute

Kochkin, S., and C.M. Rogin. 2000. "Quantifying the Obvious: The Impact of Hearing Instruments on Quality of Life.” The Hearing Review 7: 1--13.

Kricos, P. 2000. "The Influence of Nonadiological Variables on Audiological Rehabilitation Outcomes.” Ear and Hearing, vol. 21, no. 4: 7--14.

Martin, Kathleen A., Mark R. Leary, and W. Jack Rejeski. 2000. "Self-Presentational Concerns in Older Adults: Implications for Health and Well-Being.” Basic and Applied Social Psychology 22 (3): 169--179.

Ministry of Employment. 2002a. Vejledning til bekendtgørelse om beskrivelse, udvikling og vurdering af arbejdsevne.

Ministry of Employment. 2002b. Bekendtgørelse om beskrivelse, udvikling og vurdering af arbejdsevne.

Ministry of Employment, Ministry of Social Affairs, Ministry of Economic, and Business Affairs \& Ministry of Finance. 2003. Rapport fra Udvalget vedr. Lœngere tid på arbejdsmarkedet. Copenhagen: Ministry of Finance.

Ministry of Social Affairs. 2006. Bekendtgørelse om metode for god sagsbehandling ved vurdering af nedsat funktionsevne som grundlag for tildeling af handicapkompenserende ydelser efter servicelovens bestemmelser.

Ministry of Social Affairs. 2002. Bekendtgørelse af lov om social pension nr. 759 af 28.02.2002.

Morata, T.C. 2007. "Young people: Their noise and music exposures and the risk of hearing loss.” International Journal of Audiology, vol. 46, no 3: 111--112

Mulrow, C.D., C. Aguilar, J.E. Endicott, M.R. Tuley, R. Velez, W.S. Charlip, M.C. Rhodes, J.A. Hill, and L.A. DeNino. 1990. "Quality-of-life Changes and Hearing Impairment.” Annals of Internal Medicine 113: 188--194.

National Board of Health. 2007. Hvis du skal ha' høreapparat. Vejen til bedre hørelse offentlig eller privat behandling. 
Pavlovic, C.V. 1987. "Derivation of primary parameters and procedures for use in speech intelligibility predictions.” Journal of the Acoustical Society of America, vol. 82 no 2

Pope, S.K., and M. Sowers. 2000. "Functional Status and Hearing Impairments in Women at Midlife.” The Journals of gerontology. Series B: Psychological Sciences and Social Sciences, vol. 55b, no. 3: 190--194.

Ries, P.W. 1994.Prevalence and characteristics of persons with hearing trouble: United States, 1990-91. National Center for Health Statistics. Vital Health Stat Series 10, No. 188.

Shield, B. 2006. Evaluation of the Social and Economic Costs of Hearing Impairment. A report for Hear-It

Sininger, Y.S., B. Cone-Wesson, and C. Abdala. 1998. "Gender distinctions and lateral asymmetry in the low-level auditory brainstem response of the human neonate." Hearing Research, vol. 126: 58--66.

Smeeth, L., A.E. Fletcher, E. Siu-Woon, S. Stirling, M. Nunes, E. Breeze, C.J. Bulpitt, D. Jones, and A. Tulloch. 2002. "Reduced hearing, ownership, and use of hearing aids in elderly people in the UK - the MRC Trial of the Assessment and Management of Older People in the Community: a cross-sectional survey”. The Lancet vol. 359, no. 9316: $1466-1470$.

Toh, S.T, P. Lu, M. Ong, and B. Seet. 2002. "Prevalence of Hearing Disorders in Singapore Military Conscripts: A Role for Routine Auditory Screening?” Singapore Medical Journal, vol. 43. no. 12: 622--627.

UNPD - United Nations Population Division. 2006. World Population Prospects: The 2006 Revision. United Nations.

Uchida, Y., T. Nakashima, F. Ando, N. Niino, and H. Shimokata. 2003. "Prevalence of Self-perceived Auditory Problems and their Relation to Audiometric Thresholds in a Middle-aged to Elderly Population.” Acta Otolaryngol 123: 618--626.

Wilson, D.H., P.G. Walsh, L. Sanchez, A.C. Davis, A.W. Taylor, G. Tucker.and I. Meagher. 1999. "The epidemiology of hearing impairment in an Australian adult population.” International Journal of Epidemiology 28: 247--252. 
Figure 1. Sample Pure Tone Audiogram

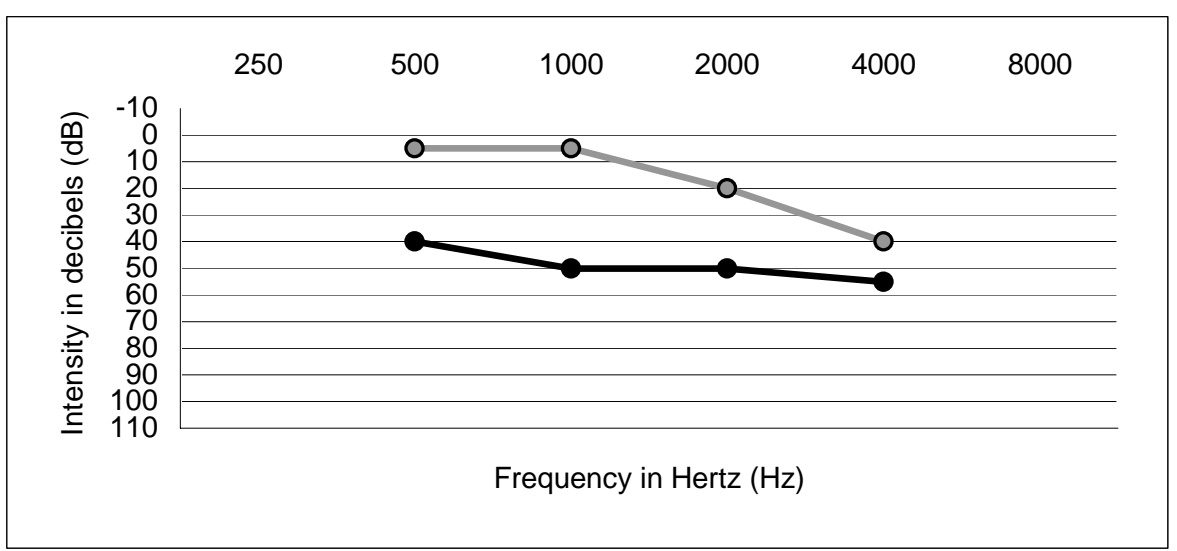

Appendix A. Estimation results for clinically measured hearing impairment (model II) using an average hearing threshold across $500-4000 \mathrm{~Hz}$ and 2000-4000 Hz respectively, separate by gender.

\begin{tabular}{|l|l|l|}
\hline & Men & Women \\
\hline Average hearing threshold for $500-4000 \mathrm{~Hz}$ & $0.003(0.43)$ & $-0.001(-0.08)$ \\
\hline Average hearing threshold for $2000-4000 \mathrm{~Hz}$ & $0.015(0.31)$ & $-0.216(-2.64)$ \\
\hline
\end{tabular}

Appendix B. Correlation between functional hearing and clinically measured hearing

\begin{tabular}{|l|l|l|l|l|l|l|l|l|l|}
\hline & \multicolumn{10}{l|}{ Functional hearing } \\
\hline & \multicolumn{1}{l}{ Number of problems in everyday life } & \\
\hline & 0 & 1 & 2 & 3 & 4 & 5 & 6 & Total & Number \\
\hline Clinical measurement & & & & & & & & & \\
\hline $15 \mathrm{~dB}-$ & 70 & 21 & 4 & 5 & 0 & 0 & 0 & & 644 \\
\hline $16 \mathrm{~dB}-25 \mathrm{~dB}$ & 64 & 25 & 7 & 3 & 1 & 0 & 0 & 100 & 630 \\
\hline $26 \mathrm{~dB}-40 \mathrm{~dB}$ & 46 & 33 & 15 & 5 & 1 & 0 & 0 & 100 & 451 \\
\hline $41 \mathrm{~dB}-55 \mathrm{~dB}$ & 25 & 36 & 25 & 11 & 1 & 2 & 0 & 100 & 168 \\
\hline $56 \mathrm{~dB}-70 \mathrm{~dB}$ & 18 & 38 & 16 & 16 & 11 & 2 & 0 & 100 & 56 \\
\hline \multicolumn{1}{|l|}{$-90 \mathrm{~dB}$} & 0 & 11 & 22 & 22 & 44 & 0 & 0 & 100 & 9 \\
\hline All & 57 & 27 & 10 & 5 & 1 & 0 & 0 & 100 & 1,958 \\
\hline
\end{tabular}

$\chi^{2}=464.986, \mathrm{df}=25, \mathrm{p}<0.0001$ 
Appendix C. Means of variables, separately by gender

\begin{tabular}{|c|c|c|c|}
\hline & & Men & Women \\
\hline Disability benefits & $=1$ on disability benefits & 0.107 & 0.174 \\
\hline Functional hearing & $\begin{array}{l}=1 \text { problems in } 2-6 \text { listening } \\
\text { situations }\end{array}$ & 0.183 & 0.150 \\
\hline Clinically measured hearing & $=-10$ to $90 \mathrm{~dB}$ & 24.913 & 17.755 \\
\hline $\begin{array}{l}\text { Clinically measured } \\
\text { hearing*health }\end{array}$ & $\begin{array}{l}=-10 \text { to } 90 \mathrm{~dB} * 1 \text { to } 10 \text { health } \\
\text { problems }\end{array}$ & 49.889 & 42.550 \\
\hline Hearing aid $^{1}$ & $=1$ hearing aid & 0.361 & 0.328 \\
\hline Assistive aids $^{2}$ & $=1$ assistive aid at workplace & 0.120 & 0.033 \\
\hline Years with hearing loss & $=10$ to 64 years & 18.494 & 16.169 \\
\hline Informed employer & $=1$ has informed employer & 0.603 & 0.596 \\
\hline Instruction & $\begin{array}{l}=1 \text { instructs in communication } \\
\text { strategies }\end{array}$ & 0.361 & 0.328 \\
\hline Age 50-64 & $=150$ years & 7.956 & 7.821 \\
\hline Age*age & Age-squared & 77.988 & 75.102 \\
\hline Basic general education & $=1$ basic general education & 0.157 & 0.213 \\
\hline Upper secondary level & $=1$ upper secondary level & 0.020 & 0.017 \\
\hline Vocational & $=1$ vocational & 0.487 & 0.342 \\
\hline Short-cycle higher education & $=1$ short-cycle higher education & 0.058 & 0.138 \\
\hline $\begin{array}{l}\text { Medium-cycle higher } \\
\text { education }\end{array}$ & $=1$ medium-cycle higher education & 0.149 & 0.218 \\
\hline Long-cycle higher education & =1 long-cycle higher education & 0.125 & 0.071 \\
\hline Occupation & $=1$ white-collar job & 0.672 & 0.763 \\
\hline Employment & $=1$ publicly employed & 0.282 & 0.548 \\
\hline Health & $=1$ to 10 health problems & 1.899 & 2.203 \\
\hline
\end{tabular}

\footnotetext{
${ }^{1}$ Means for variables: Hearing aid, Assistive aids, Years with hearing loss, Informed employer, and Instruction are reported for people with a hearing disability.

${ }^{2}$ Phone amplifiers, text phones, wire loops, fm systems, signaling- or alerting devices, technology-based communication devices, or interpreters.
} 
Appendix D. Estimates for Functional hearing

\begin{tabular}{|l|l|l|l|l|}
\hline & Men & Women & \\
\hline & Estimate & Std. err & Estimate & Std. err \\
\hline Instrumental variables & & & & \\
\hline Hearing aid only & 0.050 & 0.015 & $\begin{array}{l}0.035 \\
(1.82)^{*}\end{array}$ & 0.019 \\
& $(3.42)^{* * *}$ & & 0.037 & 0.019 \\
\hline Age*Age only & 0.060 & 0.015 & $(1.90)^{*}$ & \\
& $(4.04)^{* * *}$ & & 0.035 & 0.019 \\
\hline Both Hearing aid and & 0.050 & 0.015 & $(1.82)^{*}$ & \\
Age*Age & $(3.42)^{* * *}$ & & & \\
\hline
\end{tabular}

T-test statistics in parenthesis. Significance level: * at 10 percent, ** at 5 percent, ${ }^{* * *}$ at 1 percent

Appendix E. Estimates for Informed employer

\begin{tabular}{|l|l|l|l|l|}
\hline \multicolumn{2}{|l|}{ Men } & Women & \\
\hline & Estimate & Std. err & Estimate & Std. err \\
\hline Instrumental variables & & & & \\
\hline Instruction only & 0.073 & 0.022 & 0.165 & 0.030 \\
& $(3.32)^{* * *}$ & & $(5.52)^{* * *}$ & \\
\hline Years w. loss only & 0.042 & 0.021 & $\begin{array}{l}0.333 \\
(10.70)^{* * *}\end{array}$ & 0.031 \\
& $(1.98)^{* *}$ & & $\begin{array}{l}0.368 \\
(11.61)^{* * *}\end{array}$ & 0.032 \\
\hline $\begin{array}{l}\text { Both Instruction and Years } \\
\text { w. loss }\end{array}$ & $\begin{array}{l}0.066 \\
(3.08)^{* * *}\end{array}$ & 0.021 & & \\
\hline
\end{tabular}

T-test statistics in parenthesis. Significance level: * at 10 percent, ** at 5 percent, ${ }^{* * *}$ at 1 percent 